\title{
Factors Affecting Corneoscleral Topography
}

\author{
Lee A. Hall, ${ }^{1,2}$ Chris Hunt, ${ }^{1}$ Graeme Young, ${ }^{1,2}$ and James Wolffsohn ${ }^{1,2}$ \\ ${ }^{1}$ Visioncare Research Ltd., Farnham, United Kingdom \\ ${ }^{2}$ Aston University, Life and Health Sciences, Ophthalmic Research Group, Birmingham, United Kingdom
}

Correspondence: Lee A. Hall, Visioncare Research Ltd., Craven House, West Street, Farnham, Surrey GU9 7EN, UK;

1.hall@visioncare.co.uk.

Submitted: January 14, 2013

Accepted: March 21, 2013

Citation: Hall LA, Hunt C, Young G, Wolffsohn J. Factors affecting corneoscleral topography. Invest Ophthalmol Vis Sci. 2013;54:3691-3701. DOI: $10.1167 /$ iovs. 13-11657
Purpose. To evaluate factors affecting corneoscleral profile (CSP) using anterior segment optical coherence tomography (AS-OCT) in combination with conventional videokeratoscopy.

Methods. OCT data were collected from 204 subjects of mean age 34.9 years (SD: \pm 15.2 years, range 18-65) using the Zeiss Visante AS-OCT and Medmont M300 corneal topographer. Measurements of corneal diameter (CD), corneal sagittal height (CS), iris diameter (ID), corneoscleral junction angle (CSJ), and scleral radius (SR) were extracted from multiple OCT images. Horizontal visible iris diameter (HVID) and vertical palpebral aperture (PA) were measured using a slit lamp graticule. Subject body height was also measured. Associations were then sought between CSP variables and age, height, ethnicity, sex, and refractive error.

REsults. Significant correlations were found between age and ocular topography variables of HVID, PA, CSJ, SR, and ID $(P<0.0001)$, while height correlated with HVID, CD, and ID, and power vector terms with vertical plane keratometry, CD, and CS. Significant differences were noted between ethnicities with respect to CD $(P=0.0046)$, horizontal and vertical CS $(P=$ 0.0068 and $P=0.0095)$, and horizontal ID $(P=0.0010)$. The same variables, with the exception of vertical CS, also varied with sex; horizontal CD $(P=0.0018)$, horizontal CS $(P=$ $0.0018)$, and ID $(P=0.0012)$. Age accounted for the greatest variance in topography variables (36\%).

Conclusions. Age is the main factor influencing CSP; this should be taken into consideration in contact lens design, IOL selection, and in the optimization of surgical procedures. Ocular topography also varied with height, sex, ethnicity, and refractive error.

Keywords: corneoscleral profile, corneal topography, OCT
$\mathrm{C}$ orneal videokeratoscopy measurements provide objective data relating to the central and midperipheral corneal topography; however, information on the topography of the peripheral cornea, corneoscleral junction, and limbal sclera, which form the corneoscleral profile (CSP), is scarce. ${ }^{1}$ These data are of particular relevance in scleral contact lens fitting, and have also been shown to influence the fit of soft contact lenses, since this area is where soft contact lenses are required to make the greatest flexural changes in order to align to the ocular surface. $^{2}$

Marriott $^{3}$ first attempted to characterize the anterior ocular profile using haptic shells taken from impressions of eyes; however, his study was limited to scleral contour alone and did not consider the effect of the corneoscleral junction angle (CSJ) on corneoscleral profile. Meier and coworkers ${ }^{4,5}$ later defined the CSP, as an aid to soft contact lens fitting, based on qualitative assessments of the limbal transition zone made using the naked eye or slit lamp biomicroscope. They described five different corneoscleral transition models. Their assessments of CSP, though, were restricted to the superior corneoscleral junction, and a subsequent study ${ }^{6}$ found that this was neither an accurate or reproducible means of classification. More recently, a number of different workers ${ }^{1,2,7}$ have employed optical coherence tomography (OCT), a technique that allows for more extensive imaging of the anterior segment and peripheral corneoscleral profile. The Zeiss Visante Anterior Segment OCT (Carl Zeiss Meditec, Dublin, CA) utilizes low coherence interferometry to facilitate high-speed, noninvasive and noncontact in vivo imaging of the anterior segment, ${ }^{8,9}$ and is validated in capturing full corneal depth and width in a single scan. ${ }^{10}$

Age, height, ethnicity, sex, and manifest refraction have been identified as affecting various anterior eye dimensions such as corneal curvature, ${ }^{11}$ central corneal thickness, ${ }^{12}$ and anterior chamber depth. ${ }^{13,14}$ It is hypothesized, therefore, that they will also influence CSP variables and, hence, could be clinically relevant in contact lens design, the optimization of surgical procedures involving the cornea or sclera and also in intraocular lens (IOL) selection. The purpose of this study was to define normative corneoscleral topography data and evaluate the factors affecting the peripheral corneoscleral topography in a healthy, visually-normal population.

\section{METHODS}

A cross-sectional study was undertaken at two sites in the UK, Visioncare Research Clinic (Farnham) and Aston University (Birmingham). Subjects with preexisting ocular pathology or a history of previous ocular surgery or refractive surgery were excluded. Subjects gave written informed consent after explanation of study procedures and the study followed the tenets of the Declaration of Helsinki and was approved by the University's research ethics committee prior to commencing. 


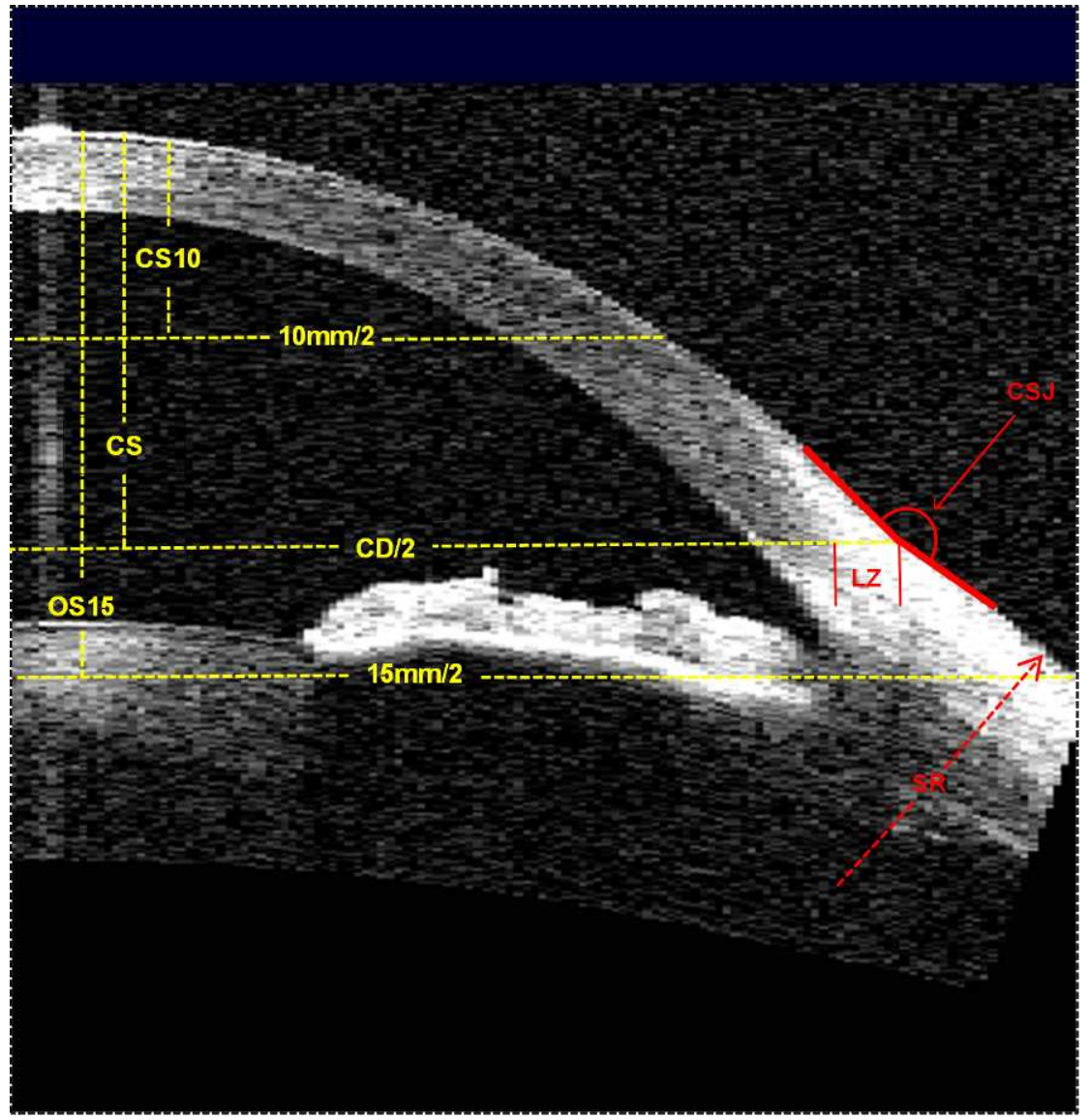

Figure 1. OCT ocular topography measurements (Table 1)

A majority of subjects identified themselves as belonging to one of two ethnicities, either Caucasian or British Asian (individuals of Indian, Pakistani, or Bangladeshi descent), and provided sufficient sample sizes to make statistical comparison between these two ethnicities. The overall ethnicity of subjects recruited was $67 \%$ Caucasian, $28 \%$ British Asian, and 5\% others.

Two hundred and four subjects (408 eyes) were imaged using the Visante Anterior Segment OCT. Vertically and horizontally scanned images were captured with the subjects' eye in the primary position, and also perpendicular images in the four cardinal directions of gaze to give full sagittal crosssections of the cornea and cross-sections of the CSJs in the vertical and horizontal meridians. External fixation targets were used to ensure consistency of subjects' direction of gaze for images taken perpendicularly. Images were corrected for distortion using the Visante's built-in, proprietary imagecorrection algorithm (Software Version 1.0.12.1896).

The Visante's internal fixation target was adjusted by the operator to compensate for the angle between the visual axis and the optical axis (angle $\alpha$ ) and carefully centered during image acquisition using the Visante's built-in alignment monitor for images acquired in primary gaze. Measurements of corneal diameter (CD), corneal sagittal height (CS), iris diameter (ID), CSJ angle, and scleral radius (SR) were extracted from the images using the Visante's built-in caliper and protractor tools (Fig. 1, Table 1). The CS of a chord at 10 $\mathrm{mm}$ (CS10), and the ocular sagittal height at $15 \mathrm{~mm}$ (OS15), were also taken. CD was defined as the distance between the two external scleral sulci. These measurements have previously been shown to be both repeatable and reliable. ${ }^{2}$
Conventional corneal topography data were collected using the Medmont E300 corneal topographer (Medmont, Camberwell, Australia). ${ }^{15,16}$ In addition to providing simulated keratometry $(\mathrm{K})$ readings, this also provided CS and corneal shape factor (SF) data. Since the Medmont E300 presents SF as $\mathrm{e}^{2}$ (where $\mathrm{e}=$ conicoidal eccentricity), the results use the convention in which a SF of zero indicates a spherical surface and a negative value indicates an oblate ellipse. Objective refraction was measured using an auto-refractor (SRW-5000; Shin-Nippon, Tokyo, Japan). ${ }^{17}$

In addition to measurement of ID by OCT, subjects' horizontal visible iris diameter (HVID), equivalent to the measurement of white-to-white (WTW), was measured using a FS2 slit lamp with built-in graticule (Nikon, Tokyo, Japan). This provided a comparison of ID, as determined by OCT, with 'visible' ID, as measured by slit lamp graticule. Measurements of vertical palpebral aperture (PA) were also taken using the slit lamp biomicroscope. The width of the limbal zone (LZ), the transition between the outer edge of the visible iris and the outer corneal sulci, was determined for each eye as the difference between the horizontal CD and ID measurements. Subjects' body height was measured to test for associations between height and ocular topography variables.

A classification of CSP was made dependent on CSJ angle, which was also demarked by the change from smooth cornea to undulating conjunctival profile. Transition zones with CSJ angles of less than $179^{\circ}$ were classified as concave (negative) zones, with angles of between $179^{\circ}$ and $181^{\circ}$ classified as 'flat' and those with angles of greater than $181^{\circ}$ classified as convex (positive). 
TABLE 1. Abbreviations of Ocular Measurement Variables

\begin{tabular}{|c|c|c|}
\hline Abbreviation & Description & Instrument \\
\hline HVID & $\begin{array}{l}\text { Horizontal visible iris diameter - } \\
\text { synonymous with WTW }\end{array}$ & $\begin{array}{l}\text { Slit lamp } \\
\text { graticule }\end{array}$ \\
\hline PA & Palpebral aperture & $\begin{array}{l}\text { Slit lamp } \\
\text { graticule }\end{array}$ \\
\hline $\mathrm{K}$ & Simulated keratometry reading & VK \\
\hline $\mathrm{SF}$ & Corneal shape factor $\left(\mathrm{SF}=\mathrm{e}^{2}\right)$ & VK \\
\hline $\mathrm{CA}$ & Corneal astigmatism & VK \\
\hline CS10-VK & $\begin{array}{l}\text { Corneal sagittal height of a chord at } \\
10 \mathrm{~mm}\end{array}$ & VK \\
\hline $\mathrm{CD}$ & Corneal diameter & OCT \\
\hline CS & $\begin{array}{l}\text { Corneal sagittal height of a chord } \\
\text { taken between the anterior corneal } \\
\text { sulci }\end{array}$ & OCT \\
\hline CS10-OCT & $\begin{array}{l}\text { Corneal sagittal height of a chord at } \\
10 \mathrm{~mm}\end{array}$ & OCT \\
\hline OS15 & $\begin{array}{l}\text { Ocular sagittal height of a chord at } 15 \\
\mathrm{~mm}\end{array}$ & OCT \\
\hline ID & Iris diameter & OCT \\
\hline CSJ & Corneoscleral junction angle & OCT \\
\hline SR & Scleral radius & OCT \\
\hline $\mathrm{LZ}$ & $\begin{array}{l}\text { Limbal zone, the transition zone } \\
\text { between the outer edge of the } \\
\text { visible iris and the outer corneal } \\
\text { sulci; where } \mathrm{LZ}=(\mathrm{CD}-\mathrm{ID}) / 2\end{array}$ & - \\
\hline$\Delta \mathrm{CD}$ & $\begin{array}{l}\text { Difference in corneal diameter } \\
\text { between the horizontal and vertical } \\
\text { meridians }\end{array}$ & - \\
\hline$\Delta \mathrm{CSJ}$ & $\begin{array}{l}\text { Difference between the two corneo- } \\
\text { scleral junction angles in a given } \\
\text { meridian }\end{array}$ & - \\
\hline $\mathrm{n}, \mathrm{t}, \mathrm{s}, \mathrm{i}$ & Nasal, temporal, superior, inferior & - \\
\hline $\mathrm{h}, \mathrm{v}$ & Horizontal, vertical & - \\
\hline
\end{tabular}

VK, videokeratoscopy.

\section{Data Analysis}

Objective refraction data were converted into the power vector terms $\mathrm{M}, J_{0}$, and $J_{45} .{ }^{18}$ The Shapiro-Wilk's test was used to evaluate any deviations from normality, using a critical value of 0.05 .

Pearson's and Spearman's correlation coefficients were used to examine similarities between right and left eyes. All variables showed strong positive correlations between right and left eyes ( $P \leq 0.0012)$, indicating that the eyes were mirrored. Therefore, only data from the right eyes were analyzed to alleviate any interocular dependency issues and statistical bias due to enantiomorphism, ${ }^{19}$ as well as to be consistent with previous studies.

Summary statistics (mean, median, SD, and range) were calculated for only the right eyes for selected variables.

Data from the horizontal and vertical meridians were compared using either paired $t$-tests or the Wilcoxon signed- rank test, depending on the distribution of the variable. The Friedman test was used to compare CSJ angle and SR data between the four quadrants (nasal, temporal, superior, and inferior). The Wilcoxon signed-rank test was also used to compare horizontal CD with both HVID and ID, using a critical value of less than or equal to 0.05 .

Spearman's rank correlation was used to examine the associations of age, sex, subject height, and power vectors with the ocular topography variables, and to examine associations between topography variables. In view of the conservative nature of multiple comparison corrections, such as Bonferroni, ${ }^{20}$ a critical value of $P$ less than or equal to 0.01 was considered significant.

CS10 data measured with both videokeratoscopy and anterior segment OCT were compared using Bland-Altman plots. ${ }^{21}$ Also, for these plots, 95\% confidence intervals (CIs) of the mean differences were calculated as $\bar{x} \pm\left[t_{1-\alpha / 2} \times S E(\bar{x})\right]$ (where $\bar{x}=$ mean difference).

Mixed model analysis was used to compare differences between sex and also ethnicity with respect to ocular topography variables. The models included subject age, sex, height, ethnicity (British Asian and Caucasian), and power vector terms as fixed factors. Since the majority (95\%) of subjects were either British Asian or Caucasian, this analysis included only these 194 subjects and excluded the remaining $5 \%$ of subjects of other ethnicity due to their small sample size. Model estimates of mean and SE were reported for the comparisons of ethnic group and sex. A $P$ value of less than or equal to 0.01 indicated a significant difference.

Data were analyzed using SPSS (PASW Version 18; IBM, Inc., Armonk, NY). Missing data were excluded from the analysis and not extrapolated from the collected data.

\section{Results}

\section{Biometric Data}

The mean age of subjects was 34.9 years $(S D \pm 15.2$, range 18 65 ) and $65 \%$ were female. The mean height of subjects was $169.0 \mathrm{~cm}$ (SD \pm 9.4 , range 152-192).

Most of the variables (73\%) showed significant variations from the normal distribution. All ocular variables showed significant correlations between right and left eyes $(P<$ 0.0012) (see Supplementary Tables S1 and S2 for further information regarding distribution and correlations between ocular variables).

The mean spherical equivalent (M) was -1.96 diopters (D) (SD $2.47 \pm 2.47$, range -10.20 to +3.50 ), $J_{0}+0.08 \mathrm{D}$ (SD \pm 0.34 , range -1.00 to $+2.90 \mathrm{D})$ and $J_{45} 0.00 \mathrm{D}(\mathrm{SD} \pm 0.17$, range -0.60 to +0.60 ) (Table 2, Fig. 2).

\section{Ocular Dimensions}

There was a wide variation in corneal shape amongst the study sample, with horizontal $\mathrm{K}$ readings ranging from 7.09 to 8.75 $\mathrm{mm}$ (mean 7.81, SD $\pm 0.30 \mathrm{~mm}$ ). As expected, the mean

Table 2. Mean Spherical Equivalent Refractive Error by Age and Sex (Right Eyes Only)

\begin{tabular}{lcccccc}
\hline & Eyes & $>-6.00 \mathbf{D}$ & $-\mathbf{6 . 0 0}$ to $-\mathbf{3 . 0 1} \mathbf{D}$ & $-\mathbf{3 . 0 0}$ to $-\mathbf{0 . 0 1} \mathbf{D}$ & Plano to $+3.00 \mathbf{D}$ & +3.01 to $+\mathbf{6 . 0 0} \mathbf{D}$ \\
\hline $18-39 \mathrm{y}$ & $127(62 \%)$ & $8(6.3 \%)$ & $24(18.9 \%)$ & $76(59.8 \%)$ & $19(15 \%)$ & $0(0 \%)$ \\
$40-65 \mathrm{y}$ & $77(38 \%)$ & $7(9.1 \%)$ & $20(26.0 \%)$ & $33(42.9 \%)$ & $16(20.8 \%)$ & $1(1.3 \%)$ \\
Male & $72(35 \%)$ & $3(4.2 \%)$ & $15(20.8 \%)$ & $48(66.7 \%)$ & $5(6.9 \%)$ & $1(1.4 \%)$ \\
Female & $132(65 \%)$ & $12(9.1 \%)$ & $29(22.0 \%)$ & $61(46.2 \%)$ & $30(22.7 \%)$ & $0(0 \%)$ \\
Total & $204(100 \%)$ & $15(7.4 \%)$ & $44(21.6 \%)$ & $109(53.4 \%)$ & $35(17.2 \%)$ & $1(0.5 \%)$ \\
\hline
\end{tabular}




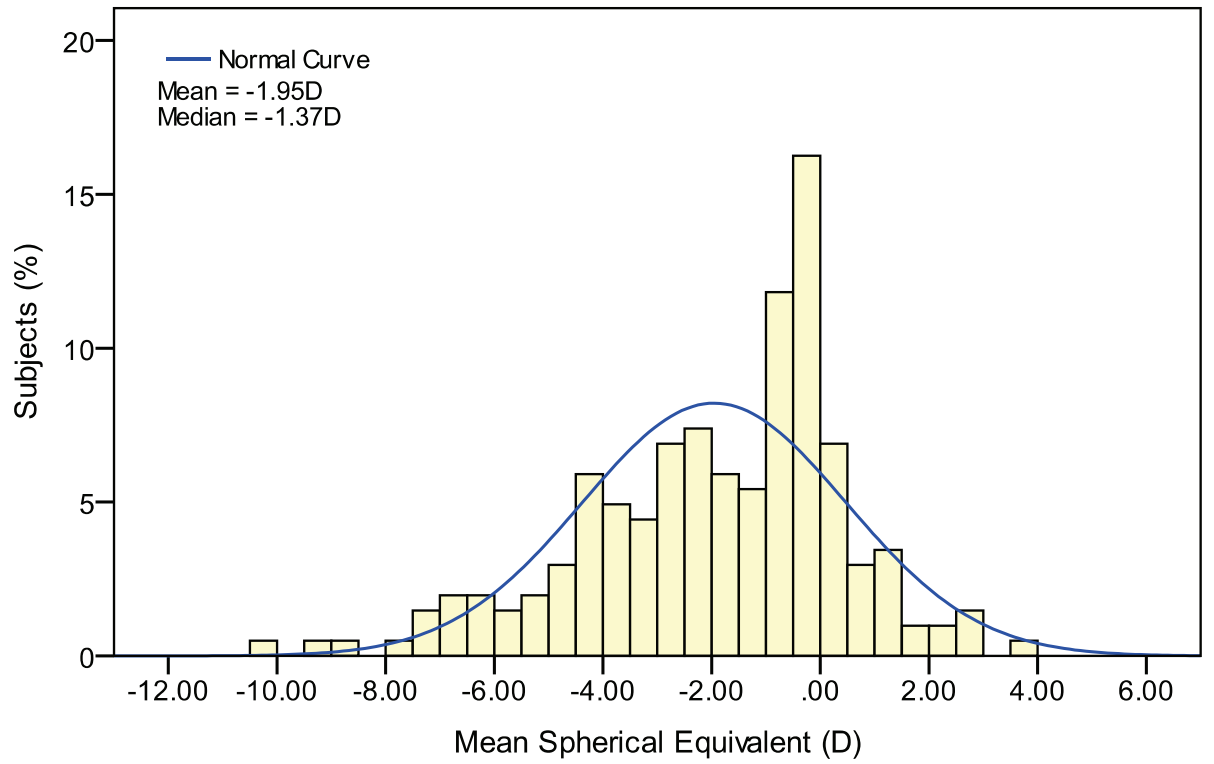

FIGURE 2. Frequency distribution of mean spherical equivalent (right eyes only).

horizontal CD was larger than HVID (13.4 vs. $11.7 \mathrm{~mm}, P<$ $0.0001)$ measured by slit-lamp, but also larger than horizontal ID measured by OCT ( 13.4 vs. $11.6 \mathrm{~mm}, P<0.0001)$. There was also a wide variation amongst the study population in LZ width, the transition zone between ID and outer corneal border $(-0.09$ to $+1.61 \mathrm{~mm})$; the mean horizontal $\mathrm{LZ}$ width was $0.94 \mathrm{~mm}(\mathrm{SD} \pm 0.18)$. The ocular topography results are summarized in Table 3. Frequency distributions of key ocular variables are shown in Figures 3 and 4.

The mean CSJ angle tended to be sharpest at the nasal CSJ and became progressively (and significantly) flatter at the temporal, inferior, and superior junctions (Friedman Test, $\chi^{2}=$ 220.1, $P<0.0001$, Table 3, Fig. 5). In many cases, CSJ angles lay within the $179^{\circ}$ to $181^{\circ}$ range, indicating almost tangential extensions of the peripheral cornea to form the sclera. This was evident in $40 \%, 24 \%, 21 \%$, and $3 \%$ of eyes at the superior, inferior, temporal, and nasal corneoscleral junctions, respectively. A breakdown of the CSP types according to CSJ angle seen is summarized in Table 4.

Scleral radius of curvature ranged from -57 to $313 \mathrm{~mm}$. The mean scleral radius was steepest in the temporal sclera, but was similar in each of the nasal, superior, and inferior scleral planes (Friedman Test, $\chi^{2}=85.1, P<0.0001$ ).

Significant differences were found between horizontal and vertical planes with respect to all variables $(P<0.01)$. The mean difference between opposing corneoscleral junctions ( $\Delta$ CSJ) (e.g., nasal and temporal) was significantly greater for the horizontal meridian than for the vertical meridian $\left(3.61^{\circ} \mathrm{vs}\right.$. $\left.1.64^{\circ}, P<0.0001\right)$

TABLE 3. Ocular Topography Variables (Right Eyes Only)

\begin{tabular}{|c|c|c|c|c|c|c|c|c|c|c|}
\hline \multirow[b]{2}{*}{ Ocular Variable } & \multicolumn{5}{|c|}{ Horizontal } & \multicolumn{5}{|c|}{ Vertical } \\
\hline & Subjects $\ddagger$ & Mean & SD & Median & Range & Subjects $\ddagger$ & Mean & SD & Median & Range \\
\hline $\mathrm{Ksim}, \mathrm{mm}$ & 202 & 7.84 & 0.30 & 7.81 & $7.09-8.75$ & 202 & 7.68 & 0.28 & 7.64 & $6.96-8.51$ \\
\hline $\mathrm{PA}, \mathrm{mm}$ & - & - & - & - & - & 196 & 10.2 & 1.4 & 10.3 & $6.6-13.4$ \\
\hline HVID, mm & 199 & 11.7 & 0.5 & 11.7 & $10.5-13.2$ & - & - & - & - & - \\
\hline $\mathrm{SF}$ & 202 & 0.46 & 0.15 & 0.44 & $0.09-0.93$ & 196 & 0.18 & 0.11 & 0.17 & $-0.44-0.53$ \\
\hline CS10-VK, mm & 202 & 1.77 & 0.08 & 1.77 & $1.53-2.03$ & 202 & 1.81 & 0.10 & 1.80 & $1.57-2.14$ \\
\hline $\mathrm{CD}, \mathrm{mm}$ & 204 & 13.4 & 0.4 & 13.5 & $12.1-14.4$ & 186 & 13.2 & 0.6 & 13.3 & $11.2-14.4$ \\
\hline $\mathrm{CS}, \mathrm{mm}$ & 204 & 3.17 & 0.20 & 3.15 & $2.57-3.71$ & 186 & 3.09 & 0.27 & 3.12 & $2.26-3.73$ \\
\hline CS10-OCT, mm & 204 & 1.75 & 0.08 & 1.75 & $1.53-1.98$ & 202 & 1.78 & 0.08 & 1.78 & $1.43-2.02$ \\
\hline OS15, mm & 202 & 3.70 & 0.17 & 3.71 & $3.23-4.08$ & 178 & 3.75 & 0.18 & 3.75 & $3.20-4.24$ \\
\hline $\mathrm{ID}, \mathrm{mm}$ & 203 & 11.58 & 0.41 & 11.57 & $10.63-12.81$ & 199 & 11.16 & 0.46 & 11.16 & $9.69-12.17$ \\
\hline $\mathrm{LZ}, \mathrm{mm}$ & 203 & 0.93 & 0.18 & 0.94 & $0.43-1.38$ & 186 & 1.03 & 0.27 & 1.06 & $-0.09 \dagger-1.61$ \\
\hline \multirow[t]{2}{*}{$\mathrm{CSJ},^{\circ}$} & 204 & $173.9 \mathrm{n}$ & 3.4 & 174.0 & $149.1-179.9$ & 200 & $178.1 \mathrm{~s}$ & 1.9 & 178.6 & $167.2-184.4^{*}$ \\
\hline & 203 & $177.0 \mathrm{t}$ & 2.4 & 177.3 & $169.5-183.8^{*}$ & 201 & $177.7 \mathrm{i}$ & 1.6 & 177.9 & $172.6-180.0$ \\
\hline \multirow[t]{2}{*}{$\mathrm{SR}, \mathrm{mm}$} & 204 & $35.5 \mathrm{n}$ & 39.4 & 22.5 & $-57.4-312.5$ & 199 & $29.3 \mathrm{~s}$ & 17.4 & 25.6 & $-19.7-142.0$ \\
\hline & 202 & $22.4 \mathrm{t}$ & 12.7 & 18.9 & $3.1-100.0$ & 201 & $33.5 \mathrm{i}$ & 29.6 & 26.1 & $9.4-313.8$ \\
\hline
\end{tabular}

* Angle of $>180^{\circ}$ signifies a convex corneoscleral junction profile.

† A minus value signifies where limbal transparency extended beyond the anterior corneal sulcus.

‡ Data could not be extracted from $<2.5 \%$ of horizontal image scans, increasing to $4.5 \%$ on average for vertical scans due to the obstruction of the upper lid. 


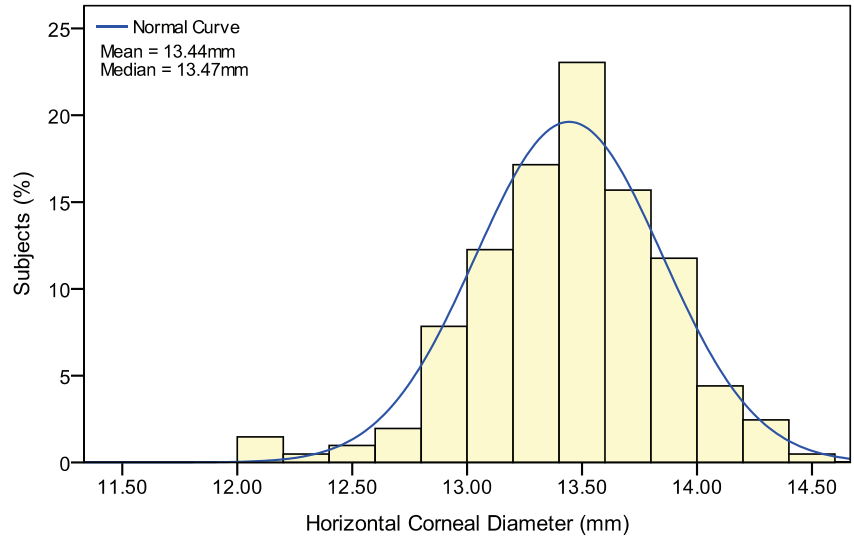

Figure 3. Frequency distribution of corneal diameter (right eyes only).

\section{Correlations Between Ocular Topography Variables}

Significant correlations were found between ocular variables and are summarized in Table 5. OCT measurements of ID correlated strongly with those of HVID measured with slit-lamp graticule $(r=+0.68, P<0.0001)$. Corneal astigmatism was not significantly correlated with the difference in vertical and horizontal corneal diameter (i.e., $\Delta \mathrm{CD})(r=+0.12, P=0.12)$.

The only measurement derived from both videokeratoscopy and OCT was CS10, which showed a significant correlation between the two measurement techniques $(r=+0.87, P<$ 0.0001 ; mean difference $+0.02 \pm 0.01 \mathrm{~mm}[95 \% \mathrm{CI}]$ and $r=$ $+0.78, P<0.0001$; mean difference $+0.02 \pm 0.01 \mathrm{~mm}[95 \%$ $\mathrm{CI}]$, for the horizontal and vertical meridians, respectively) (Fig. 6).

\section{Factors Affecting Ocular Topography Variables}

Significant correlations were found between various ocular variables and age, height, mean spherical equivalent, and cylindrical power vector terms. However, age correlated with the greatest number of variables and had stronger associations than the other continuous variables (Table 6).

Subject age contributed to variance in the greatest number of ocular topography variables, while subject height did not influence variance (Table 7). Age alone accounted for up to

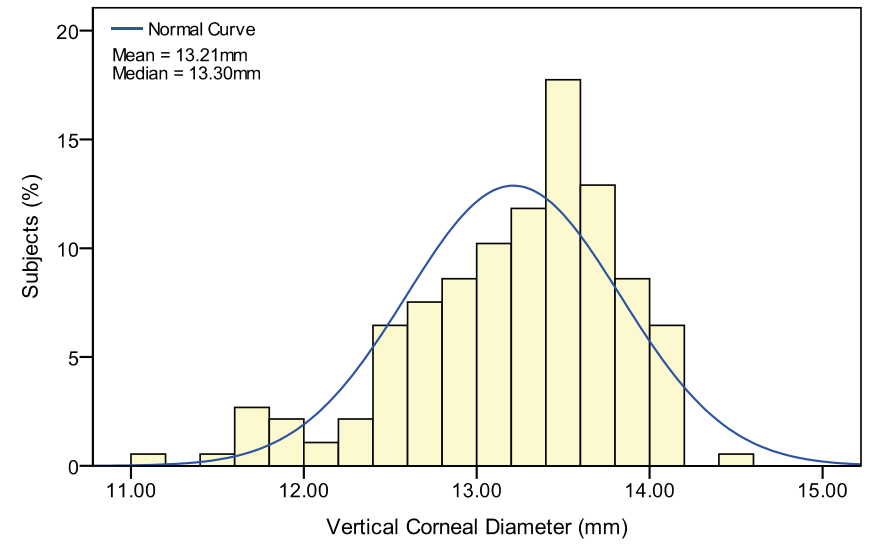

$36 \%, 33 \%, 24 \%, 23 \%$, and $13 \%$ of the variance in CSJ, SR, ID, $\mathrm{CD}$, and SF, respectively.

Significant differences were found between Caucasian and British Asian topographies with respect to horizontal CD $(P=$ $0.0046)$, both horizontal and vertical CS $(P=0.0068$ and $P=$ $0.0095)$ and horizontal ID $(P=0.0010)$. The same ocular topography variables, with the exception of vertical CS, were also found to vary with sex, horizontal CD $(P=0.0018)$, horizontal CS $(P=0.0018)$, and ID $(P=0.0012)$ (Table 8$)$.

\section{Discussion}

Advances in technology have allowed a more extensive assessment of the ocular topography. Subjective evaluation of corneal reflection (Placido Disc) was superseded by the quantification of the separation of keratometry mires. The advent of photokeratoscopy, and more latterly digital imaging and advances in computing power (videokeratoscopy), have allowed further quantification of the separation of multiple mires extending over a wider area of the cornea to determine more peripheral corneal shape. Recent technologies, such as Scheimpflug imaging, have allowed the profiling of the anterior eye surface onto the less reflective sclera, but the development of OCT has enabled detailed imaging of the peripheral corneoscleral topography. We have previously shown that characterization of the CSP using OCT is both repeatable and reliable. $^{2}$
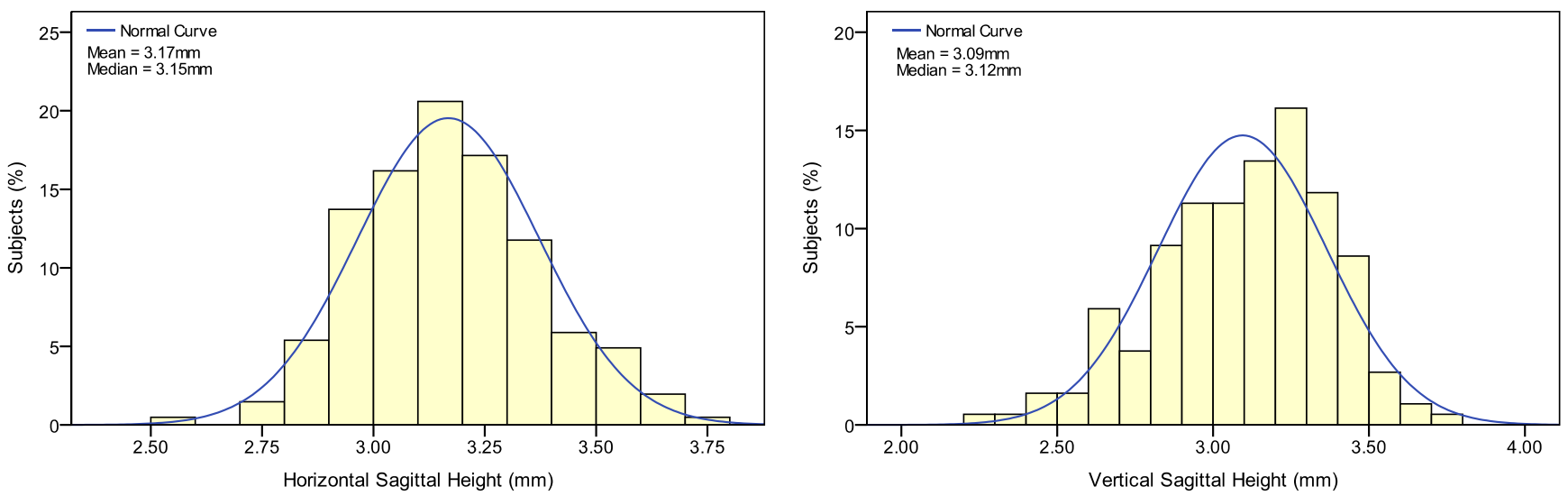

FiguRE 4. Frequency distribution of corneal sagittal height (right eyes only). 


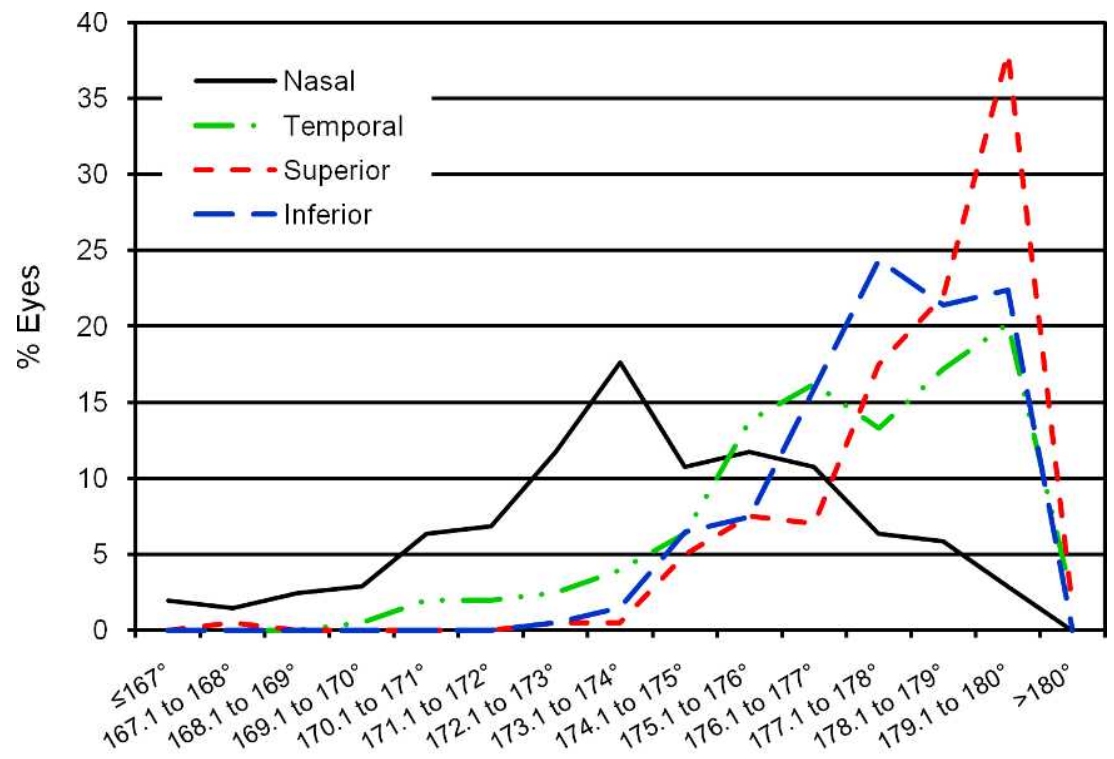

Corneoscleral Junction Angle $\left({ }^{\circ}\right)$

Figure 5. Frequency distribution of corneoscleral junction angles (right eyes only).

TABle 4. Classifications of Corneoscleral Profile According to Corneoscleral Junction Angle (Right Eyes Only)

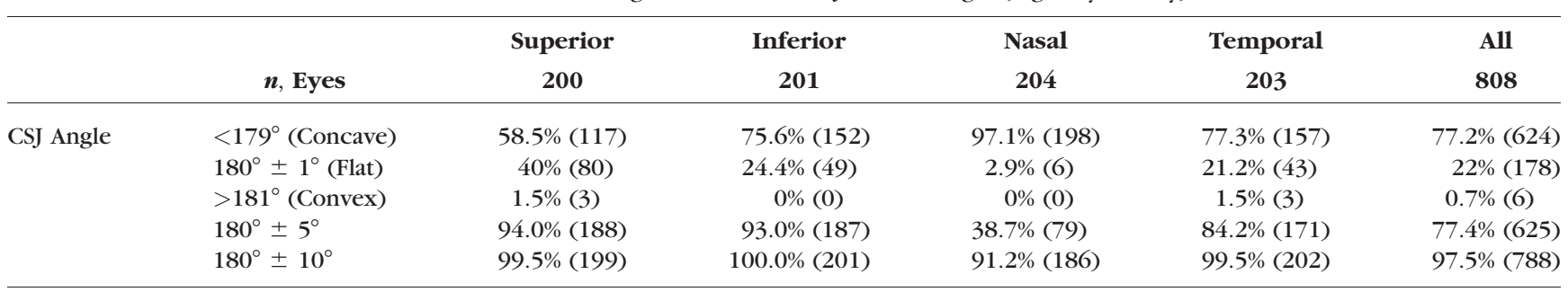

An understanding of this ocular topography has application in scleral contact lens practice, has been shown to influence soft contact lens fitting characteristics, and also has implications for refining the positioning of corneal incisions and the

TABLE 5. Significant Correlations Between Ocular Variables (Right Eyes Only)

\begin{tabular}{lcccc}
\hline Variable & $\boldsymbol{n}$, Eyes & $\begin{array}{c}\text { Ocular } \\
\text { Variable }\end{array}$ & $\begin{array}{c}\text { Correlation } \\
\text { Coefficient, } \boldsymbol{R}\end{array}$ & $\boldsymbol{P}$ Value \\
\hline ID & 198 & HVID & +0.68 & $<0.001$ \\
CDh & 199 & HVID & +0.43 & $<0.001$ \\
& 203 & IDh & +0.55 & $<0.001$ \\
CDv & 186 & CSv & +0.80 & $<0.001$ \\
& 181 & HVID & +0.37 & $<0.001$ \\
CSh & 204 & CDh & +0.63 & $<0.001$ \\
& 202 & SFh & -0.46 & $<0.001$ \\
CSv & 186 & CDv & +0.80 & $<0.001$ \\
LZh & 203 & CDh & +0.43 & $<0.001$ \\
& 203 & CSh & +0.34 & $<0.001$ \\
& 203 & IDh & -0.45 & $<0.001$ \\
& 185 & LZv & +0.39 & $<0.001$ \\
LZv & 186 & CDv & +0.61 & $<0.001$ \\
& 186 & CSv & +0.47 & $<0.001$ \\
& 185 & LZh & +0.39 & $<0.001$ \\
CSJn & 199 & SRn & +0.29 & $<0.001$ \\
CSJt & 181 & SRt & +0.29 & $<0.001$ \\
\hline \multicolumn{2}{c}{$P$ values of } & $\leq 0.01$ were considered significant. &
\end{tabular}

determination of optimum IOL parameters. The factors likely to affect corneoscleral topography include subject height, refractive error size, sex, ethnicity, and aging. The purpose of this study was to evaluate these factors, in a healthy population, and to determine their effect on the peripheral corneoscleral topography.

Although biologic variables are usually normally distributed, many of the variables in this study did not show a normal distribution. While this could be thought to be linked to refractive error, since refractive error is typically skewed due to incomplete emmetropization, the correlations with ocular topography did not support this rationale as few ocular variables were significantly correlated with refractive error. Most of the ocular variables were correlated with age and, as the age of our sample was not normally distributed, this would seem the most likely explanation for this observation.

Several smaller scale studies have utilized OCT to define anterior segment metrics. ${ }^{22,23}$ This study supports the findings of our previous work and also provides normative data for a larger, wider population.

Two important clinically relevant findings were drawn from this study. First, 'true' CD, as assessed by OCT, was greater than that previously found using more conventional techniques. In defining the CSP an appreciation of the corneoscleral junction at the corneal sulcus, and, therefore, CD is required. Various other methods have been used to determine $\mathrm{CD},{ }^{24-32}$ amongst which, automated methods of WTW CD measurement have previously been shown to provide more precise results than manual methods of measurement. ${ }^{24}$ In this study the mean 


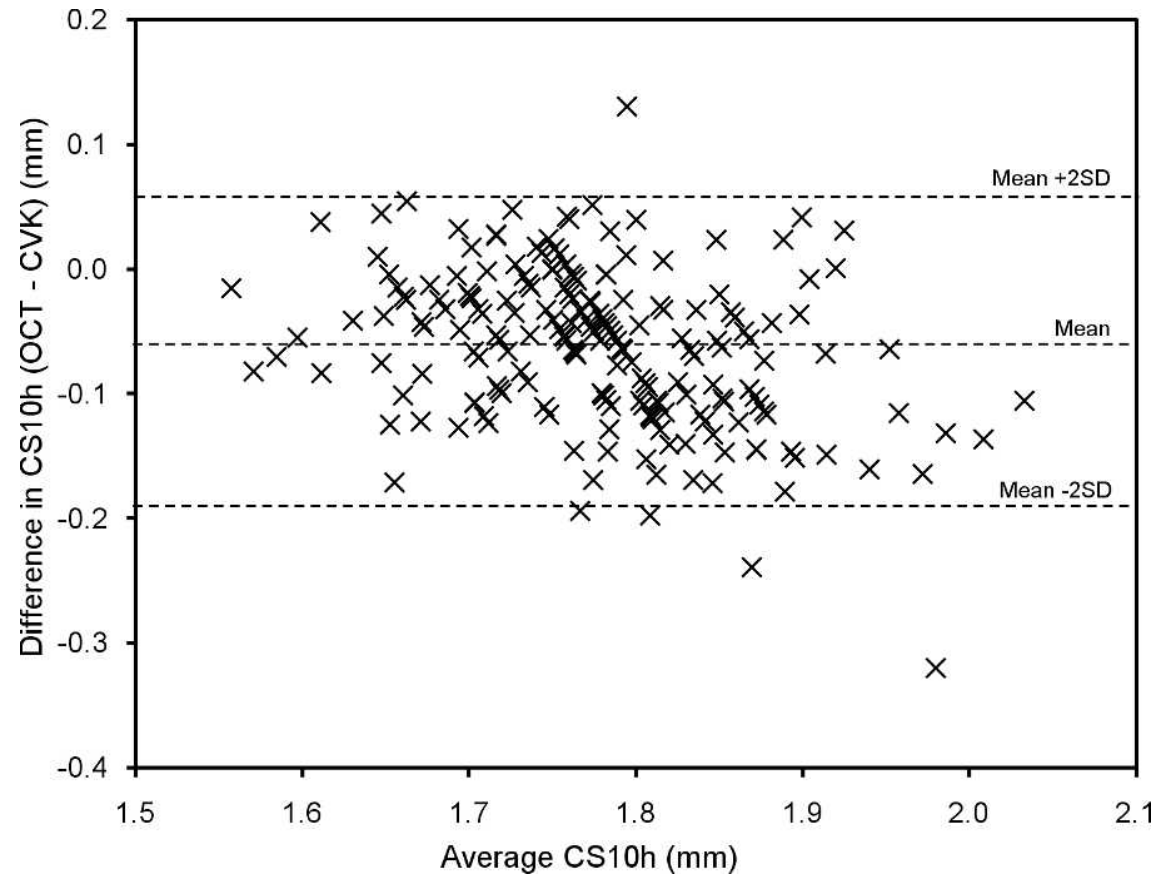

FiguRE 6. Comparison of the horizontal corneal sagittal height measurements of a chord at $10 \mathrm{~mm}$ by computerized videokeratoscopy and OCT and the average measurement (right eyes only), showing the $95 \%$ limits after Bland-Altman.

TABLE 6. Significant Correlations With Subject Age, Height, and Refractive Error (Right Eyes Only)

\begin{tabular}{|c|c|c|c|c|c|c|c|c|c|c|c|c|c|c|c|}
\hline \multirow[b]{2}{*}{ Variable } & \multicolumn{3}{|c|}{ Age } & \multicolumn{3}{|c|}{ Height } & \multicolumn{3}{|c|}{ Mean Equivalent Sphere } & \multicolumn{3}{|c|}{$J_{0}$} & \multicolumn{3}{|c|}{$J_{45}$} \\
\hline & $\mathbf{P}$ & $\mathbf{R}$ & $\mathbf{N}$ & $\mathbf{P}$ & $\mathbf{R}$ & $\mathbf{N}$ & $\mathbf{P}$ & $\mathbf{R}$ & $\mathbf{N}$ & $\mathbf{P}$ & $\mathbf{R}$ & $\mathbf{N}$ & $\mathbf{P}$ & $\mathbf{R}$ & $\mathbf{N}$ \\
\hline HVID & $<0.0001$ & -0.40 & 199 & 0.0016 & 0.23 & 189 & 0.85 & -0.01 & 198 & 0.0013 & 0.23 & 198 & 0.61 & -0.04 & 198 \\
\hline PA & $<0.0001$ & -0.34 & 196 & 0.11 & 0.12 & 186 & 0.046 & -0.14 & 195 & 0.015 & 0.17 & 195 & 0.46 & 0.05 & 195 \\
\hline $\mathrm{Kh}$ & 0.25 & -0.08 & 202 & 0.076 & 0.13 & 192 & 0.033 & 0.15 & 201 & 0.24 & 0.08 & 201 & 0.65 & -0.03 & 201 \\
\hline $\mathrm{Kv}$ & 0.37 & -0.06 & 202 & 0.011 & 0.18 & 192 & 0.0030 & 0.21 & 201 & 0.018 & -0.17 & 201 & 0.71 & -0.03 & 201 \\
\hline SFh & 0.092 & 0.12 & 202 & 0.73 & -0.02 & 192 & 0.12 & 0.11 & 201 & 0.018 & 0.17 & 201 & 0.37 & -0.06 & 201 \\
\hline $\mathrm{SFv}$ & 0.096 & 0.12 & 196 & 0.19 & -0.10 & 186 & 0.46 & -0.05 & 195 & 0.97 & 0.00 & 195 & 0.92 & 0.01 & 195 \\
\hline CS10h-VK & 0.078 & 0.12 & 202 & 0.034 & -0.15 & 192 & 0.16 & -0.10 & 201 & 0.30 & -0.07 & 201 & 0.56 & 0.04 & 201 \\
\hline CS10v-VK & 0.69 & -0.03 & 202 & 0.15 & -0.11 & 192 & 0.041 & -0.14 & 201 & 0.16 & 0.10 & 201 & 0.53 & 0.04 & 201 \\
\hline $\mathrm{CDh}$ & 0.14 & -0.10 & 204 & 0.026 & 0.16 & 194 & 0.0097 & -0.18 & 203 & 0.20 & 0.09 & 203 & 0.018 & 0.17 & 203 \\
\hline $\mathrm{CDv}$ & 0.064 & -0.14 & 186 & 0.0073 & 0.20 & 177 & 0.66 & -0.03 & 185 & 0.67 & -0.03 & 185 & 0.86 & -0.01 & 185 \\
\hline$\Delta \mathrm{CD}$ & 0.29 & 0.08 & 186 & 0.25 & -0.09 & 177 & 0.13 & -0.11 & 185 & 0.48 & 0.05 & 185 & 0.068 & 0.13 & 185 \\
\hline CSh & 0.15 & -0.10 & 204 & 0.093 & 0.12 & 194 & 0.0001 & -0.27 & 203 & 0.70 & 0.03 & 203 & 0.0054 & 0.19 & 203 \\
\hline CSv & 0.022 & -0.17 & 186 & 0.019 & 0.18 & 177 & 0.20 & -0.09 & 185 & 0.81 & -0.02 & 185 & 0.34 & 0.07 & 185 \\
\hline CS10h-OCT & 0.87 & 0.01 & 204 & 0.21 & -0.09 & 194 & 0.12 & -0.11 & 203 & 0.39 & -0.06 & 203 & 0.63 & 0.03 & 203 \\
\hline CS10v-OCT & 0.34 & -0.07 & 202 & 0.18 & -0.10 & 192 & 0.0035 & -0.20 & 201 & 0.0031 & 0.21 & 201 & 0.21 & 0.09 & 201 \\
\hline OS15h & 0.63 & -0.03 & 202 & 0.83 & 0.02 & 192 & 0.050 & -0.14 & 201 & 0.34 & -0.07 & 201 & 0.25 & 0.08 & 201 \\
\hline OS15v & 0.062 & -0.14 & 178 & 0.26 & 0.09 & 171 & 0.099 & -0.12 & 177 & 0.34 & 0.07 & 177 & 0.042 & 0.15 & 177 \\
\hline IDh & 0.013 & -0.17 & 203 & 0.012 & 0.18 & 193 & 0.97 & 0.00 & 202 & 0.46 & 0.05 & 202 & 0.21 & 0.09 & 202 \\
\hline IDv & $<0.0001$ & -0.29 & 199 & 0.0069 & 0.20 & 189 & 0.75 & -0.02 & 198 & 0.99 & 0.00 & 198 & 0.88 & -0.01 & 198 \\
\hline LZh & 0.20 & 0.09 & 203 & 0.62 & -0.04 & 193 & 0.0065 & -0.19 & 202 & 0.68 & 0.03 & 202 & 0.31 & 0.07 & 202 \\
\hline $\mathrm{LZv}$ & 0.25 & 0.08 & 186 & 0.90 & 0.01 & 177 & 0.88 & -0.01 & 185 & 0.51 & -0.05 & 185 & 0.59 & -0.04 & 185 \\
\hline CSJn & 0.011 & -0.18 & 204 & 0.23 & 0.09 & 194 & 0.078 & 0.12 & 203 & 0.77 & 0.02 & 203 & 0.20 & -0.09 & 203 \\
\hline CSJt & $<0.0001$ & -0.35 & 203 & 0.26 & 0.08 & 193 & 0.045 & 0.14 & 202 & 0.39 & -0.06 & 202 & 0.58 & -0.04 & 202 \\
\hline$\Delta \mathrm{CSJh}$ & 0.76 & -0.02 & 203 & 0.80 & -0.02 & 193 & 0.51 & 0.05 & 202 & 0.24 & -0.08 & 202 & 0.32 & 0.07 & 202 \\
\hline CSJs & 0.70 & -0.03 & 200 & 0.57 & -0.04 & 190 & 0.15 & 0.10 & 199 & 0.77 & -0.02 & 199 & 0.66 & 0.03 & 199 \\
\hline CSJi & 0.40 & 0.06 & 201 & 0.49 & -0.05 & 191 & 0.38 & 0.06 & 200 & 0.16 & 0.10 & 200 & 0.26 & 0.08 & 200 \\
\hline$\Delta \mathrm{CSJv}$ & 0.77 & -0.02 & 199 & 0.70 & -0.03 & 189 & 0.40 & -0.06 & 198 & 0.16 & -0.10 & 198 & 0.43 & -0.06 & 198 \\
\hline SRn & $<0.0001$ & -0.41 & 204 & 0.22 & 0.09 & 194 & 0.15 & -0.10 & 203 & 0.016 & 0.17 & 203 & 0.44 & -0.05 & 203 \\
\hline SRt & $<0.0001$ & -0.32 & 202 & 0.12 & 0.11 & 192 & 0.28 & -0.08 & 201 & 0.20 & 0.09 & 201 & 0.51 & 0.05 & 201 \\
\hline SRs & $<0.0001$ & -0.51 & 199 & 0.34 & 0.07 & 189 & 0.40 & -0.06 & 198 & 0.042 & 0.14 & 198 & 0.42 & 0.06 & 198 \\
\hline SRi & $<0.0001$ & -0.36 & 201 & 0.72 & 0.03 & 191 & 0.022 & -0.16 & 200 & 0.15 & 0.10 & 200 & 0.80 & -0.02 & 200 \\
\hline
\end{tabular}

Spearman's rank correlation was used as all variable pairs included at least one non-normally distributed variable. $P$ values of $\leq 0.01$ were considered significant (significant variables in bold above). 
TABLE 7. Summary of Multivariate Analysis

\begin{tabular}{|c|c|c|c|c|c|c|c|c|c|c|c|c|c|c|c|}
\hline \multirow[b]{2}{*}{ Variable } & \multirow{2}{*}{$\begin{array}{c}\text { Total } \\
\text { Variance } \\
\text { of Model } \\
r^{2}\end{array}$} & \multicolumn{2}{|c|}{ Ethnicity } & \multicolumn{2}{|c|}{ Subject Age } & \multicolumn{2}{|c|}{$\operatorname{Sex}$} & \multicolumn{2}{|c|}{ Height } & \multicolumn{2}{|c|}{ M } & \multicolumn{2}{|l|}{$J_{0}$} & \multicolumn{2}{|c|}{$J_{45}$} \\
\hline & & $\begin{array}{c}P \\
\text { Value }\end{array}$ & $\begin{array}{c}\mathbf{F} \\
\text { Stat. }\end{array}$ & $\begin{array}{c}P \\
\text { Value }\end{array}$ & $\begin{array}{c}\mathbf{F} \\
\text { Stat. }\end{array}$ & $\begin{array}{c}\boldsymbol{P} \\
\text { Value }\end{array}$ & $\begin{array}{c}\text { F } \\
\text { Stat. }\end{array}$ & $\begin{array}{c}P \\
\text { Value }\end{array}$ & $\begin{array}{c}\mathbf{F} \\
\text { Stat. }\end{array}$ & $\begin{array}{c}P \\
\text { Value }\end{array}$ & $\begin{array}{c}\mathbf{F} \\
\text { Stat. }\end{array}$ & $\begin{array}{c}P \\
\text { Value }\end{array}$ & $\begin{array}{c}\mathbf{F} \\
\text { Stat. }\end{array}$ & $\begin{array}{c}P \\
\text { Value }\end{array}$ & $\begin{array}{c}\mathbf{F} \\
\text { Stat. }\end{array}$ \\
\hline HVID & 0.38 & 0.30 & 1.07 & 0.0036 & 8.71 & 0.22 & 1.52 & 0.026 & 5.04 & 0.38 & 0.79 & $<0.0001$ & 21.39 & 0.76 & 0.10 \\
\hline PA & 0.28 & 0.54 & 0.38 & 0.0005 & 12.58 & 0.12 & 2.50 & 0.74 & 0.11 & 0.092 & 2.87 & 0.20 & 1.69 & 0.081 & 3.09 \\
\hline $\mathrm{Kh}$ & 0.22 & 0.58 & 0.30 & 0.51 & 0.44 & 0.59 & 0.29 & 0.22 & 1.51 & 0.0006 & 12.19 & 0.0001 & 15.69 & 0.21 & 1.60 \\
\hline $\mathrm{Kv}$ & 0.18 & 0.95 & 0.00 & 0.24 & 1.38 & 0.28 & 1.16 & 0.38 & 0.78 & 0.0012 & 10.90 & 0.34 & 0.91 & 0.24 & 1.40 \\
\hline SFh & 0.17 & 0.68 & 0.17 & 0.024 & 5.20 & 0.98 & 0.00 & 1.00 & 0.00 & 0.0062 & 7.68 & 0.0001 & 16.71 & 0.45 & 0.58 \\
\hline SFv & 0.13 & 0.12 & 2.45 & 0.0085 & 7.09 & 0.76 & 0.09 & 0.86 & 0.03 & 0.81 & 0.06 & 0.45 & 0.58 & 0.57 & 0.33 \\
\hline CS10h-VK & 0.19 & 0.73 & 0.12 & 0.050 & 3.90 & 0.61 & 0.26 & 0.30 & 1.08 & 0.017 & 5.82 & 0.0007 & 11.81 & 0.48 & 0.51 \\
\hline CS10v-VK & 0.11 & 0.77 & 0.08 & 0.94 & 0.01 & 0.58 & 0.31 & 0.53 & 0.40 & 0.0051 & 8.04 & 0.60 & 0.28 & 0.62 & 0.25 \\
\hline $\mathrm{CDh}$ & 0.21 & 0.0046 & 8.25 & 0.00 & 8.06 & 0.0018 & 10.01 & 0.17 & 1.87 & 0.049 & 3. & .11 & 2.52 & 0.13 & 2.36 \\
\hline $\mathrm{CDv}$ & 0.23 & 0.046 & 4.03 & 0.0068 & 7.52 & 0.16 & 2.02 & 0.74 & 0.11 & 0.92 & 0.01 & 0.22 & 1.52 & 0.47 & 0.53 \\
\hline $\mathrm{CSh}$ & 0.23 & 0.0068 & 7.71 & 0.054 & 3.76 & 0.0018 & 10.09 & 0.12 & 2.38 & 0.0003 & 13.34 & 0.33 & 0.94 & 0.32 & 1.00 \\
\hline CSv & 0.26 & 0.0095 & 6.89 & 0.0003 & 13.42 & 0.085 & 2.99 & 0.97 & 0.00 & 0.18 & 1.84 & 0.16 & 1.95 & 0.18 & 1.83 \\
\hline CS10h-OCT & 0.15 & 0.51 & 0.43 & 0.38 & 0.78 & 0.77 & 0.09 & 0.50 & 0.45 & 0.0096 & 6.86 & 0.0028 & 9.21 & 0.33 & 0.95 \\
\hline CS10v-OCT & 0.14 & 0.71 & 0.14 & 0.49 & 0.48 & 0.74 & 0.11 & 0.46 & 0.55 & 0.0040 & 8.49 & 0.24 & 1.41 & 0.89 & 0.02 \\
\hline OS15h & 0.18 & 0.066 & 3.46 & 0.93 & 0.01 & 0.086 & 2.98 & 0.35 & 0.90 & 0.0070 & 7.44 & 0.0034 & 8.82 & 0.87 & 0.03 \\
\hline OS15v & 0.10 & 0.30 & 1.10 & 0.022 & 5.36 & 0.14 & 2.25 & 0.62 & 0.24 & 0.24 & 1.37 & 0.65 & 0.21 & 0.053 & 3.79 \\
\hline IDh & 0.21 & 0.0010 & 11.73 & 0.0055 & 7.90 & 0.0012 & 10.76 & 0.54 & 0.37 & 0.47 & 0.53 & 0.12 & 2.49 & 0.14 & 2.25 \\
\hline IDv & 0.24 & 0.48 & 0.49 & 0.0001 & 16.43 & 0.030 & 4.80 & 0.88 & 0.02 & 0.85 & 0.03 & 0.57 & 0.32 & 0.16 & 1.97 \\
\hline $\mathrm{LZh}$ & 0.11 & 0.88 & 0.02 & & 0.53 & 0.98 & 0.00 & 0.50 & 0.45 & 0.018 & 5.67 & 0.97 & 0.00 & 0.87 & 0.03 \\
\hline LZv & 0.26 & 0.82 & 0.05 & 0.48 & 0.50 & 0.72 & 0.13 & 0.73 & 0.12 & 0.94 & 0.01 & 0.38 & 0.77 & 0.81 & 0.06 \\
\hline CSAn & 0.36 & 0.044 & 4.12 & 0.0009 & 11.34 & 0.47 & 0.52 & 0.55 & 0.35 & 0.042 & 4.19 & 0.84 & 0.04 & 0.69 & 0.16 \\
\hline CSAt & 0.18 & 0.20 & 1.67 & $<0.0001$ & 25.44 & 0.91 & 0.01 & 0.87 & 0.03 & 0.057 & 3.65 & 0.93 & 0.01 & 0.60 & 0.28 \\
\hline CSAs & 0.22 & 0.82 & 0.05 & 0.71 & 0.14 & 0.99 & 0.00 & 0.97 & 0.00 & 0.091 & 2.88 & 0.52 & 0.41 & 0.11 & 2.65 \\
\hline CSAi & 0.11 & 0.84 & 0.04 & 0.87 & 0.03 & 0.38 & 0.76 & 0.49 & 0.48 & 0.20 & 1.67 & 0.16 & 2.03 & 0.12 & 2.49 \\
\hline SRn & 0.17 & 0.62 & 0.25 & 0.0024 & 9.46 & 0.13 & 2.37 & 0.69 & 0.16 & 0.26 & 1.27 & 0.60 & 0.27 & 0.60 & 0.28 \\
\hline SRt & 0.22 & 0.30 & 1.08 & 0.031 & 4.74 & 0.34 & 0.92 & 0.26 & 1.27 & 0.56 & 0.35 & 0.96 & 0.00 & 0.30 & 1.09 \\
\hline SRs & 0.33 & 0.57 & 0.32 & $<0.0001$ & 17.58 & 0.59 & 0.29 & 0.42 & 0.65 & 0.80 & 0.07 & 0.78 & 0.08 & 0.13 & 2.26 \\
\hline SRi & 0.17 & 0.16 & 2.00 & 0.21 & 1.60 & 0.082 & 3.06 & 0.75 & 0.10 & 0.092 & 2.86 & 0.48 & 0.50 & 0.092 & 2.86 \\
\hline
\end{tabular}

Mixed model analysis with ethnicity, age, sex, height, $\mathrm{M}, J_{0}$, and $J_{45}$ as fixed effects. $P$ values of $\leq 0.01$ were considered significant (significant variables in bold above).

horizontal CD was consistent with that of our previous study (13.4 $\mathrm{mm}$ in both), but was greater than that reported by Martin and Holden ${ }^{26}$ using a photographic method $(12.9 \mathrm{~mm})$, and also of other studies reporting WTW values. Of these, the three largest studies evaluating WTW data reported mean values ranging from 11.7 to $12.1 \mathrm{~mm}$. These utilized scanningslit technology (Orbscan; Bausch \& Lomb, Claremont, CA) ${ }^{31,32}$ and a photographic method (LenStar LS 900; Haag Streit AG, Koeniz, Switzerland/IOLMaster; Carl Zeiss AG, Jena, Germany). ${ }^{25} \mathrm{CD}$, however, as defined by the measurement of WTW (or HVID), is confounded by the three-dimensional transparency profile of the peripheral cornea. This, in turn, is further complicated by the fact that enface imaging is not normal to the peripheral cornea. The rate of change of transparency also differs widely, as highlighted by the variation in limbal zone width seen in this study. This is particularly noticeable vertically, as evidenced by the greater difference between HVID and ID seen in this meridian. In addition, the loss of transparency is not uniform across the depth of the cornea, and is not consistent between the quadrants.

WTW has been shown to be a poor predictor of capsular bag diameter in determining IOL size ${ }^{33,34}$ which may, in part, be explained by the issues inherent with enface measurement. WTW is also used to determine IOL power; however, a better measure of $\mathrm{CD}$ such as that utilized in this study may enable better refractive outcomes.
Second, the junction between the cornea and the sclera is often portrayed as a sharp transition. ${ }^{35}$ However, in this study, $77 \%$ of CSJ angles were within $5^{\circ}$ of $180^{\circ}$ and approximately one-fifth were within $\pm 1^{\circ}$, demonstrating an almost tangential extension of the cornea to form the paralimbal sclera in those cases.

The difference between opposing corneoscleral junction angles $(\Delta \mathrm{CSJ})$ was significantly greater in the horizontal meridian compared with the vertical. Our previous study ${ }^{2}$ has shown a link between increasing differences in horizontal CSJ angles ( $\triangle$ CSJh) and lens tightness for soft contact lenses; it is likely that this difference limits horizontal contact lens movement in comparison with that in the vertical meridian. However, given the small differential between superior and inferior CSJ angles ( $\triangle$ CSJv), any restriction in contact lens movement in this meridian is unlikely to be due to the transitions at the corneoscleral junctions. Kikkawa ${ }^{36}$ proposed a model where a soft lens could be considered as a series of concentric elastic bands that stretch and flex to accommodate changes in the ocular topography. Subsequently, any restriction in movement in the vertical meridian is more likely to be due to raised squeeze pressure acting to recenter the lens with increasing decentration, as it is forced to undergo greater stretching and flexing to align with the scleral topography.

It is likely that decreases in CSJ magnitude, resulting in sharper, more acute CSJ transitions, may also contribute to 3and 9-o'clock corneal staining in rigid contact lens wear as a 


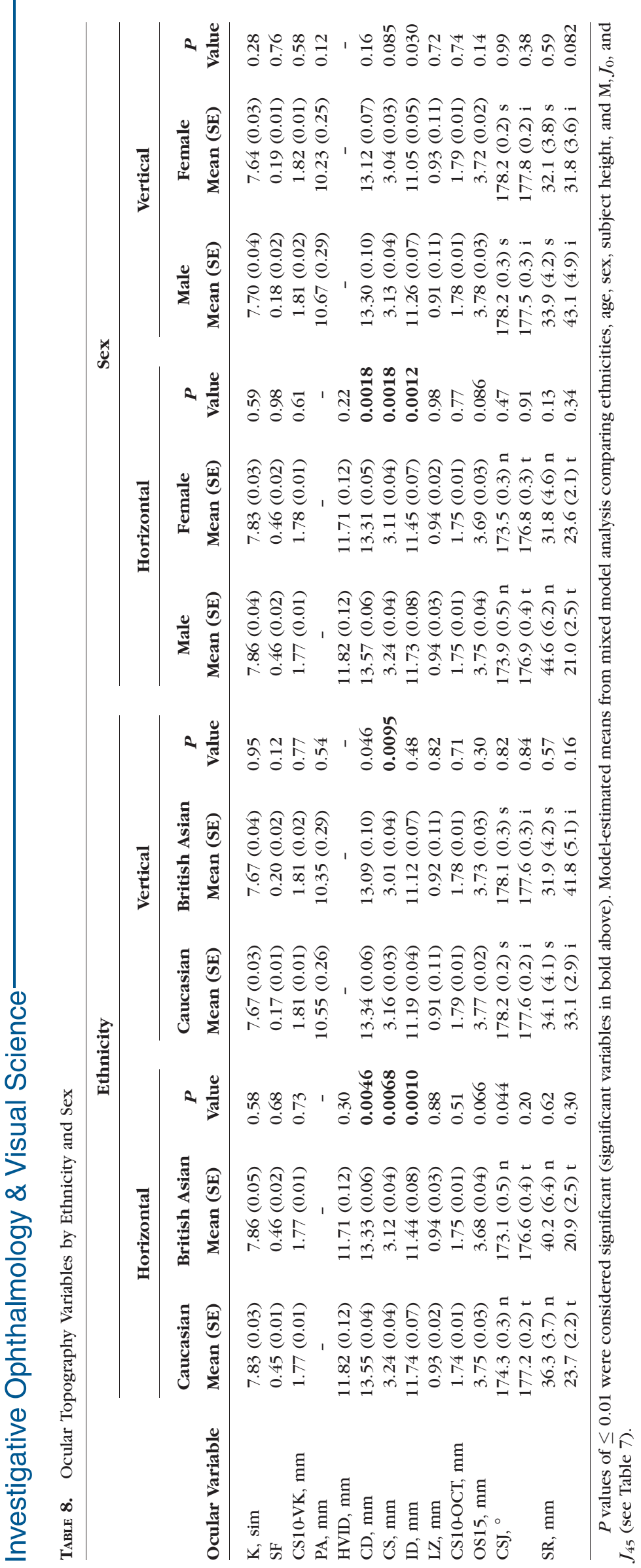


result of an increased gap between the ocular surface and inner eyelid due to lens thickness, so called 'bridge effect'. ${ }^{37}$

As independent variables, height and refractive error were both found to correlate with ocular topography. The correlation of height with ocular topography agrees with the findings of a previous study that found taller subjects had larger eyes with flatter corneas, ${ }^{38}$ although this may have been influenced by general nutrition. However, height did not account for any of the variance in CSP within the multivariate model.

Age was the most important factor influencing CSP variables, resulting in decreases in variable magnitude with increasing age. This agrees with the findings of a previous OCT study investigating the effects of age on ocular variables. ${ }^{13}$ These are most likely to be due to the natural physiological changes associated with ageing. This is evidenced by the decreases in SR and CSJ angle, resulting in steepening of radius and CSJ angle, respectively. These are likely due to the accumulation of fatty deposits (e.g., pingueculae) across the horizontal conjunctival face. The decreases in the non-CSP variables, PA fissure size and ID, due to a loss in muscle tone and as result of increasing peripheral corneal opacification with age, respectively, would also support this. CD, however, was not found to be influenced by age. This finding would emphasize the unreliability of ID as a surrogate for CD, particularly given the significant decrease in ID with age seen in this study.

As with sex, ethnicity influenced CD, CS, and ID. These were independent of height and age, and, hence, must be related to some other genetic factor. In comparing ocular variables between ethnicities, though, this study was limited to Caucasians and British Asians and is, therefore, not necessarily representative of Asians throughout the Pacific Rim.

In conclusion, this study has shown that age is the main factor influencing corneoscleral topography; hence, age should be taken into consideration in contact lens design, in the optimization of surgical procedures involving the cornea or sclera and also in IOL lens selection.

\section{Acknowledgments}

The authors thank Amit Jinabhai, Louise Nicklin, Bernard Gilmartin, and Hetal Patel for their assistance in the preparation of this paper.

Supported by grants from Johnson \& Johnson Visioncare.

Disclosure: L.A. Hall, Visioncare Research Ltd. (F, E); C. Hunt, Visioncare Research Ltd. (E); G. Young, Visioncare Research Ltd. (E); J. Wolffsohn, Visioncare Research Ltd. (E)

\section{References}

1. van der Worp E, Graf T, Caroline P. Exploring beyond the corneal borders. Cont Lens Spect. 2010;25:27-32.

2. Hall LA, Young G, Wolffsohn JS Riley C. The influence of corneoscleral topography on soft contact lens fit. Invest Ophthalmol Vis Sci. 2011;52:6801-6806.

3. Marriott PJ. An analysis of the global contours and haptic contact lens fitting. Br J Pbysiol Opt. 1966;23:1-40.

4. Gaggioni M, Meier D. The corneo scleral profile [in German]. Neues Optiker. 1987;1:66-71.

5. Meier D. Das corneo-skleral-profil-ein kriterium individueller kontaktlinsenanpassung. Die Kontaklinse. 1992;26:4-11.

6. Bokern S, Hoppe M Bandlitz S. Accuracy and repeatability in the classification of the corneo-scleral profile [in German]. Die Kontaklinse. 2007;7:26-28.

7. Feng Y, Simpson TL. Comparison of human central cornea and limbus in vivo using optical coherence tomography. Optom Vis Sci. 2005;82:416-419.
8. Sakata LM, Wong TT, Wong HT, et al. Comparison of Visante and slit-lamp anterior segment optical coherence tomography in imaging the anterior chamber angle. Eye. 2010;24:578-587.

9. Leung CK, Cheung CY, Li H, et al. Dynamic analysis of darklight changes of the anterior chamber angle with anterior segment OCT. Invest Ophthalmol Vis Sci. 2007;48:4116-4122.

10. Dunne M, Davies L, Wolffsohn J. Accuracy of cornea and lens biometry using anterior segment optical coherence tomography. J Biomed Opt. 2007;12:064023.

11. Goto T, Klyce SD, Zheng X, et al. Gender- and age-related differences in corneal topography. Cornea. 2001;20:270-276.

12. Doughty MJ, Zaman ML. Human corneal thickness and its impact on intraocular pressure measures: a review and metaanalysis approach. Surv Ophthalmol. 2000;44:367-408.

13. Qin B, Zhou XT, Huang D, Chu RY. Effects of age on ocular anterior segment dimensions measured by optical coherence tomography. Chin Med J (Engl). 2011;124:1829-1834.

14. Leung CK, Palmiero PM, Weinreb RN, et al. Comparisons of anterior segment biometry between Chinese and Caucasians using anterior segment optical coherence tomography. $\mathrm{Br} \mathrm{J}$ Ophthalmol. 2010;94:1184-1189.

15. Tang W, Collins MJ, Carney L, Davis B. The accuracy and precision performance of four videokeratoscopes in measuring test surfaces. Optom Vis Sci. 2000;77:483-491.

16. Cho P, Lam AK, Mountford J, Ng L. The performance of four different corneal topographers on normal human corneas and its impact on orthokeratology lens fitting. Optom Vis Sci. 2002;79:175-183.

17. Mallen EA, Wolffsohn JS, Gilmartin B, Tsujimura S. Clinical evaluation of the Shin-Nippon SRW-5000 autorefractor in adults. Ophthalmic Physiol Opt. 2001;21:101-107.

18. Thibos LN, Wheeler W, Horner D. Power vectors: an application of Fourier analysis to the description and statistical analysis of refractive error. Optom Vis Sci. 1997;74:367-375.

19. Ray WA, O'Day DM. Statistical analysis of multi-eye data in ophthalmic research. Invest Ophthalmol Vis Sci. 1985;26: 1186-1188.

20. Hochberg Y, Benjamini Y. More powerful procedures for multiple significance testing. Stat Med. 1990;9:811-818.

21. Bland JM, Altman DG. Statistical methods for assessing agreement between two methods of clinical measurement. Int J of Nurs Stud. 2010;47:931-936.

22. Sorbara L, Maram J, Fonn D, Woods C, Simpson T. Metrics of the normal cornea: anterior segment imaging with the Visante OCT. Clin Exp Optom. 2010;93:150-156.

23. Qin B, Tang M, Li Y, et al. Anterior segment dimensions in Asian and Caucasian eyes measured by optical coherence tomography. Ophthalmic Surg Lasers Imaging. 2012;43:135142.

24. Baumeister M, Terzi E, Ekici Y, Kohnen T. Comparison of manual and automated methods to determine horizontal corneal diameter. $J$ Cataract Refract Surg. 2004;30:374-380.

25. Buckhurst PJ, Wolffsohn JS, Shah S, et al. A new optical low coherence reflectometry device for ocular biometry in cataract patients. Br J Ophthalmol. 2009;93:949-953.

26. Martin DK, Holden BA. A new method for measuring the diameter of the in vivo human cornea. Am J Optom Physiol Opt. 1982;59:436-441.

27. Nemeth G, Hassan Z, Szalai E, Berta A, Modis L Jr. Comparative analysis of white-to-white and angle-to-angle distance measurements with partial coherence interferometry and optical coherence tomography. J Cataract Refract Surg. 2010;36: 1862-1866.

28. Pinero DP, Plaza Puche AB, Alio JL. Corneal diameter measurements by corneal topography and angle-to-angle measurements by optical coherence tomography: evaluation of equivalence. J Cataract Refract Surg. 2008;34:126-131. 
29. Pop M, Payette Y, Mansour M. Predicting sulcus size using ocular measurements. J Cataract Refract Surg. 2001;27:10331038.

30. Potgieter FJ, Roberts C, Cox IG, et al. Prediction of flap response. J Cataract Refract Surg. 2005;31:106-114.

31. Rufer F, Schroder A, Erb C. White-to-white corneal diameter: normal values in healthy humans obtained with the Orbscan II topography system. Cornea. 2005;24:259-261.

32. Srivannaboon S, Chotikavanich S. Corneal characteristics in myopic patients. J Med Assoc Thai. 2005;88:1222-1227.

33. Werner L, Izak AM, Pandey SK, et al. Correlation between different measurements within the eye relative to phakic intraocular lens implantation. J Cataract Refract Surg. 2004; 30:1982-1988.
34. Khng C, Osher RH. Evaluation of the relationship between corneal diameter and lens diameter. J Cataract Refract Surg. 2008;34:475-479.

35. Van Buskirk EM. The anatomy of the limbus. Eye. 1989;3:101108

36. Kikkawa Y. Kinetics of soft contact lens fitting. Contacto. 1979;23:10-17.

37. van der Worp E, De Brabander J, Swarbrick H, Nuijts R, Hendrikse F. Corneal desiccation in rigid contact lens wear: 3and 9-o'clock staining. Optom Vis Sci. 2003;80:280-290.

38. Nangia V, Jonas JB, Matin A, et al. Body height and ocular dimensions in the adult population in rural Central India. The Central India Eye and Medical Study. Graefes Arch Clin Exp Ophthalmol. 2010;248:1657-1666. 